Journal of

Molecular Microbiology

and Biotechnology
J Mol Microbiol Biotechnol 2008;15:31-40

DOI: $\underline{10.1159 / 000111990}$

\title{
Metabolically Engineered Yeasts: 'Potential' Industrial Applications
}

\author{
Paola Branduardi Carla Smeraldi Danilo Porro \\ Department of Biotechnology and Biosciences, University of Milano-Bicocca, Milan, Italy
}

\section{Key Words}

Metabolic engineering $\cdot$ Yeasts $\cdot$ Industrial biotechnology

\section{Abstract}

Industrial biotechnology and metabolic engineering can offer an innovative approach to solving energy and pollution problems. The potential industrial applications of yeast are reviewed here.

Copyright $\odot 2008$ S. Karger AG, Basel

\section{Introduction}

With constantly fast-growing world population, the two mayor concerns faced today are the supplies of energy and water (for a list of the top ten see table 1). The demand for energy and water is rapidly rising. Globally, the push toward a richer lifestyle is more and more evident. New economies with double-digit growth rates, such as China and India, are absorbing more fossil fuels. It is forecasted, for example, that China's energy consumption will be 5 quadribillion British thermal units higher than that of the US by 2030 [US Department of Energy, www.eia.doe.gov].

The consequences of this situation are varied (from environment to politics, to economics) and need to be

\section{KARGER}

Fax +4161306 1234

E-Mail karger@karger.ch

www.karger.com
(C) 2008 S. Karger AG, Basel

$1464-1801 / 08 / 0151-0031 \$ 24.50 / 0$

Accessible online at:

www.karger.com $/ \mathrm{mmb}$ tackled from many points of view (from energy and water saving and equal distribution, to lifestyle changes, to an increase in industrial process efficiency, to energy production, for example). The consequences on the environment are already evident on a local scale with a high level of pollution in all industrialized countries: all major Asian cities are good examples of a rapid economy that is not sustainable from an environmental point of view. On the global scale we are experiencing climate changes. As a consequence of the increasing concentration of the socalled greenhouse gases in the atmosphere, the earth is

Table 1. Top ten issues concerning the entire humanity as listed by R.E. Smalley, 1996 Nobel Prize for Chemistry

\section{Energy}

Water

Food

Environment

Poverty

Terrorism and war

Disease

Education

Democracy

Population

Population in 2000: 6 billion people

Population in 2050: 8-10 billion people 
Fig. 1. Trends in global temperatures from 1900 to 2000. Adapted from the School of Environmental Sciences, Climatic Research Unit, University of East Anglia, UK, 1999. http://maps.grida.no/go/graphic/trends_in_global_temperatures.

Fig. 2. Oil price increments from 1970 to 2007 and major world events. Adapted from the Official Energy Statistics of the US Government: www.eia.doe.gov. $\mathrm{A}=$ 1973 oil embargo; $\mathrm{B}=1978$ Iranian revolution; C $=1980$ Iran-Iraq War begins, oil prices peak; $\mathrm{D}=1986$ Saudis abandon 'swing producer' role, oil prices collapse; $\mathrm{E}=1990$ Iraq invades Kuwait; $\mathrm{F}=1991$ Operation Desert Storm; G = 1997-1998 Asian economic crisis, oil oversupply, prices fall sharply; $\mathrm{H}=1999-2000$ OPEC cutbacks, prices rise sharply, increased demand; $I=9 / 11$ attack; $J$ = 2002 Venezuela unrest, significant increase in oil prices; $\mathrm{K}=$ 2002-2004 strong demand growth; $\mathrm{L}=2005$ Hurricanes Katrina and Rita strike gulf coast; $\mathrm{M}=$ oil price April 2007.
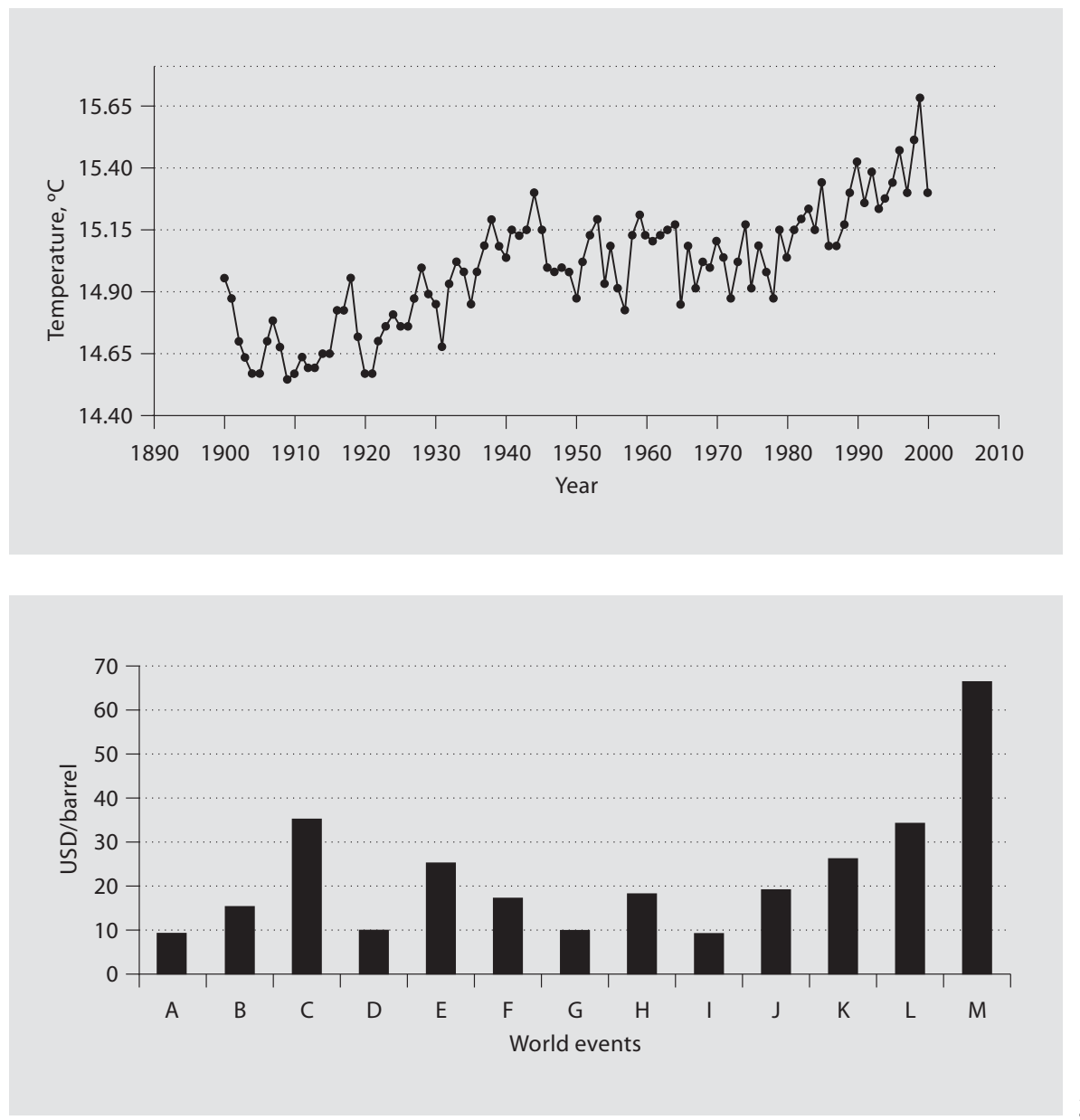

expected to become warmer (fig. 1). The main contributor of global warming is $\mathrm{CO}_{2}$, primarily resulting from the burning of fossil resources (coal, petroleum and natural gas) in addition to other factors such as deforestation of tropical forests. In 1997, thirty-nine of the world's richest countries agreed to curb greenhouse gas emissions at the Kyoto Climate Change Conference. However, it should be underlined that the resulting Kyoto Protocol, enacted in February 2005, has had little impact because it does not require developing countries to cut their emissions, and because the USA has not embraced it.

The increase in demand for fossil fuels is also reflected in their price increase and their depletion. Figure 2 shows the price increments from 1970 to 2007. With regards to fossil reserves, we are now faced with the paradoxical situation that while crude oil (petroleum) is being consumed faster than ever, the 'proven oil reserves' have remained at about the same level as 30 years ago due to new oil findings. Nevertheless, these 'proven oil reserves' are located in increasingly difficult to reach places. Therefore, the cost of extracting crude oil rises continuously as reflected by the increasing oil prices. More important in this respect is that the world's crude oil reserves will not last forever. In a comprehensive study on global energy outlooks by the World Energy Council [www.worldenergy.org], several future scenarios have been envisioned and developed. It is generally assumed that petroleum will be exhausted in about 50 years, natural gas in 65 years and coal in about 200 years. Last but not least, the prices and availability of natural resources are conditioned by world politics.

Fossil fuels, besides their use to produce energy, act as building blocks or reagents for fabricating several materials. There are many non-fuel uses for petroleum, including various specialized products used in the chemical, textile, metallurgical, electrical, and other industries. A partiallist of the non-fuel uses of petroleum includes: solvents (such as those used in paints, lacquers, and printing 
inks); lubricating oils and greases (for automobile engines and other machinery); petroleum or paraffin wax (used in candy making, packaging, candles, matches, and polishes); petrolatum jelly (sometimes blended with paraffin wax in medical products and toiletries); asphalt (used to pave roads and airfields, to surface canals and reservoirs, and to make roofing materials and floor coverings); petroleum coke (used as a raw material for many carbon and graphite products, including furnace electrodes and liners, and anodes used in the production of aluminum), and petroleum feedstocks (used as chemical feedstock derived from petroleum principally for the manufacture of chemicals, synthetic rubber, and a variety of plastics). Final common products made from crude oil include: ink, heart valves, crayons, parachutes, floor wax, telephones, brassieres, tapes, antiseptics, purses, deodorants, pantyhose, shoes, volleyballs, cosmetics, sneakers, bubble gum, car bodies, tires, house paints, eyeglasses, life jackets, fertilizers, movie film, combs, basketballs, to name just a few. This list is only a sampling of the products made from crude oil. It is not intended to be all-inclusive. Rather it is meant to show in just how many areas products made from crude oil are found and used. All of these products increase the demand of fossil fuel, are non-biodegradable, and their production contributes to the generation of $\mathrm{CO}_{2}$ and consequently to global warming. Considering these statements and the previously described scenario, it is clear that it is now more than ever urgent to find alternatives to the use of oil, both in the production of energy and for the production of non-fuel petroleum-derived products.

This review will provide an overview on the latter aspect, showing the potential of metabolically engineered yeasts in this respect.

\section{Metabolically Engineered Yeasts: Industrial Biotechnology Applications}

The strategies to solve the environmental and energy issues mentioned above are many. Solar, nuclear and wind energy, each with their own advantages and disadvantages, offer good alternatives to petroleum for energy production. An innovative approach offering some solutions comes from industrial biotechnology (IB) and metabolic engineering (ME), both for the production of biofuels and for the manufacturing of non-fuel petroleumderived products. IB, defined also as white biotechnology, already offers some solutions and, in perspective, it has a huge potential. In this respect, IB uses renewable raw ma- terials as starting products and microorganisms (genetically modified or not) and their enzymes to make useful chemical compounds and biomaterials. While its application in the production of fine chemicals and pharmaceuticals is already well established (e.g. insulin, interferons, erythropoietin, hepatitis $B$ vaccine, vitamin $B_{12}$, etc.), it is now increasingly being applied to produce bulk chemicals such as biofuels (e.g. ethanol) and bioplastics. Other fields of application include food additives and supplements, colorants, vitamins, nutraceuticals, cosmeceuticals, pesticides, solvents, enzymes, bioenergy, etc. [Suschem, 2005; Bio - Biotechnology Industry Organization, 2007; BREW, 2006; US Department of Energy 2004, 2003]. This technological platform presents the inherent advantages of a clean process that can reduce water and energy consumption, have less or no waste generation and less $\mathrm{CO}_{2}$ generation. Additionally, the costs of new biotechnological processes could be $40 \%$ lower than those of conventional processes and could imply up to $70 \%$ savings on capital equipment.

Microorganisms (prokaryotic as well as eukaryotic) are widely used in IB applications. They are advantageous hosts because of the high growth rates and the common ease of genetic manipulation. In this respect, the dominance of Escherichia coli as host for the production of metabolites, heterologous proteins, enzymes, aromatic compounds, amino acids, etc., is clearly a reflection of the quantity and quality of the information available about its genetic, molecular biology, biochemical, physiological and fermentation technologies. Among the microbial eukaryotic hosts systems, yeasts combines the advantages of unicellular organisms (i.e., ease of genetic manipulation and growth) with the ability of a protein processing typical of eukaryotic organisms (i.e. protein folding, assembly and post-translational modifications), together with the absence of endotoxins as well as oncogenic or viral DNA. As for E. coli, this is a reflection of the familiarity of molecular biologists with this yeast combined with deep knowledge about its genetics, biochemistry, physiology and fermentation technologies. The choice of the yeast host is of paramount importance for the success of a whole industrial process. Saccharomyces cerevisiae, the most important yeast because of its industrial significance, is recognized by the American Food and Drug Administration as an organism generally regarded as safe (GRAS), it does not produce toxins and has been used safely for centuries in the brewing and baking industries. Because of its importance both in basic research and biotechnology, S. cerevisiae was the first eukaryote to have its genome completely sequenced [Goffeau et al., 1996]. 
However, it has to be said that sometimes this yeast is not an optimal host for large-scale production. Its technical fermentation needs require highly sophisticated equipment, the proteins produced by $S$. cerevisiae are often hyper-glycosylated and retention of the products within the periplasmic space is frequently observed. Additionally it is not highly resistant to severe stresses $(\mathrm{pH}$, temperature, etc.) often imposed by the production process itself. Since the mid 1980s, these disadvantages have promoted a search for alternative hosts, trying to exploit the great biodiversity existing among yeasts. Applied research using the so-called 'non-conventional' yeasts has been developed. The most established or prominent examples of non-conventional yeasts are Hansenula polymorpha [Sudbery et al., 1988], Pichia pastoris [Thill et al., 1987], Kluyveromyces lactis [Blondeau, et al., 1994], Yarrowia lipolytica [Muller et al., 1998] , Pichia methanolica [Raymond et al., 1998], Pichia stipitis [Den Haan and Van Zyl, 2001], Zygosaccharomyces rouxii [Ogawa, et al., 1990] and Zygosaccharomyces bailii [Branduardi et al., 2004], Candida boidinii [Sakai et al., 1995], and Schwanniomyces (Debaryomyces) occidentalis [Buckholz and Gleeson, 1991], to mention a few.

In order to improve the production of metabolites already produced by the yeast cell, to extend the substrate range for growth and product formation, for the production of chemicals new to the host organism or for the modification of cell properties, ME can be used. In this respect, the only objective of $\mathrm{ME}$ is to improve the production of a metabolite/compound, homologous or heterologous, optimizing in this way the yield (grams of product obtained by gram of substrate), production (grams per liter) and productivity (grams per liter and hour) values which could finally lead to the development of a true industrial process. When we talk about ME we easily forget how young this science is. Its definition goes back to 1991, when Bailey defined it as 'the improvement of cellular activities by manipulations of enzymatic, transport, and regulatory functions of the cell with the use of recombinant DNA technology' [Bailey, 1991]. Metabolic pathway manipulation for improving the properties and productivity of microorganisms had been already done in the past changing the external or the internal environment of the cell. Manipulations of cell performance, changing the external environment, have long been practiced by choosing operating conditions during bioprocesses to improve growth, production and productivity. Traditionally, internal changes have been achieved by random mutagenesis and selection, searching for empiric changes that render the cells more active for the desired metabolic process. This approach made use of chemical mutagens and, very often, creative selection techniques to identify superior strains. There are many examples of this strategy in the area of antibiotics, amino acids, vitamins, alcohol, solvents and others. However, despite the widespread acceptance of many successes, mutagenesis remains essentially a random process. $\mathrm{ME}$ is a more complex approach. Theoretically, its core concept is that it has to consider the whole set of biochemical reactions that take place in a microorganism. Scientists have first to characterize the microorganism of choice from the metabolic point of view, analyzing the pathway involved in forming the product and how this pathway interacts with the overall cell functions. This is valid both in the case where the product of interest is already made by the cell as well as for recombinant strains constructed ad hoc. The rapid development and numerous successes in this field are demonstrated by the large number of reviews about ME [Cameron and Chaplen, 1997; Cameron and Tong, 1993; Kern et al., 2007; Nielsen, 1998, 2001; Ostergaard et al., 2000; Stephanopoulos, 1994, 1999; Stephanopoulos and Sinskey, 1993; Stephanopoulos and Vallino, 1991; Tyo et al., 2007]. The reader is invited to consult them for a comprehensive description of the theoretical platforms and experimental procedures required for the development of ME applications.

As the compilation of an exhaustive list of all the compounds that can be obtained using a ME approach in yeast and that could have 'potential' industrial applications would take a lot of space, the authors decided to describe in detail some of the main examples pertaining to three classes: wine yeasts; bulk chemicals for pharma and food applications, and bulk chemicals for industrial applications. Although there are numerous technological applications of non-conventional yeasts, $\mathrm{ME}$ has been performed almost exclusively with $S$. cerevisiae because of its GRAS status and the quantity and quality of the information available about it (see above).

\section{Wine Yeasts}

Wine yeasts are yeasts whose metabolism has been improved for wine production. About 150 different wine yeast strains, mainly S. cerevisiae, are commercially available. It has to be said that $S$. cerevisiae is not a significant producer of enzymes with relevance in wine production, but it is widely used for its GRAS status and the deep knowledge about its genetic and biochemistry. Additionally, because of negative consumer reaction, the only 
strains that have been approved for commercial utilization are the ones in which the heterologous DNA utilized for strain improvement derives from the host species, a sort of 'self-cloning' [Schuller and Casal, 2005]. It has to be noted that for wine production, as well as for many other food and industrial productions, the S. cerevisiae strains utilized are not the classical and well-known haploid 'lab strains', but are wild types. These yeasts are therefore at least diploids, and in some cases even polyploids. The disadvantages of a slightly more complicated genetic manipulation is compensated by the huge advantage of wild strains that, generally speaking, are much more stress-resistant and robust during a fermentation process. In general, the most important targets for strain improvement relate to production technology and quality improvement, such as enhancement of fermentation performance, higher ethanol tolerance, better sugar utilization and nitrogen assimilation, and improvement in organoleptic properties. Referring to fermentation performance, it is important to highlight that during wine production yeast cells are affected by several stress conditions that could affect their viability and fermentation efficiency. Cardona et al. [2007] describe a novel genetic manipulation strategy designed to improve stress resistance. This strategy involves modifying the expression of the transcription factor MSN2, which plays an important role in yeast stress responses. The promoter in one of the genomic copies of this gene has been replaced by the promoter of the SPI1 gene, encoding for a protein important in the structure and biogenesis of the cell wall. The choice of this promoter was derived from a transcriptomic analysis showing its strong activity in stationary phase of growth, in later stages of vinification [Rossignol et al., 2003], and as a consequence of several stress conditions [Gasch et al., 2000]. This modification allows self-induction of MSN2 expression, determining an improvement in resistance to several stress conditions, and a lag phase reduction during the vinification process. Moreover, cells containing this promoter are able to carry out vinifications at $15^{\circ} \mathrm{C}$ as well as at $30^{\circ} \mathrm{C}$ with higher fermentation rates during the first days of the process compared to the control strain.

With respect to the improvement in organoleptic properties, instead, a redirection of carbon fluxes through pathways alternative to the naturally occurring ones seems to be a suitable strategy. Sometimes high levels of acetic acid are produced during fermentation, affecting the quality of wine. It is possible to reduce the excretion of acetate by $S$. cerevisiae deleting the aldehyde dehydrogenase gene $(A L D 6 ;-40$ to $70 \%)$ and rerouting the carbon flux towards glycerol, succinate and butanediol, the socalled 'pyruvate dehydrogenase bypass' [Remize et al., 2000].

Another undesirable byproduct is represented by hydrogen sulfide formation. Site-directed mutagenesis of the sulfite-reductase MET10 gene was used to develop wine yeast with a lowered ability to produce the said compound [Sutherland et al., 2003].

Finally, to the best of our knowledge, the $M L 01$, a malolactic S. cerevisiae strain constructed to de-acidify high acid grape must, is the first commercialized genetically enhanced yeast.

In recent years, there has been increased consumer interest in low-alcohol, and de-alcoholized wines, resulting in a search for new production methods. Wines containing 1.8-2.0\% less alcohol were obtained from glucose oxidase overexpressing strains, since this enzyme also produced L-glucono- $\delta$-lactone and gluconic acid from glucose, lowering the quantity of carbon available for alcoholic fermentation [Malherbe et al., 2003].

The negative perception of public opinion towards the use of genetically modified organisms in wine or more generally food productions has prevented a wider use of genetically modified strains in commercial productions, although many strains have been developed. We refer the reader to Pretorious [2000] and Pretorius et al. [2003] for an extensive list of improved S. cerevisiae strains.

\section{Bulk Chemicals for Pharma and Food Applications}

Yeasts have long been utilized as very efficient biocatalysts, thanks to their enzymatic capabilities, native or manipulated. This approach was used to obtain, starting from fatty acids, many and different lipid-derived flavors and fragrances (musk fragrances, methyl ketones, esters, green notes, to name a few), responding to the increasing consumer demand for natural products and sustainable processes [Wache et al., 2006]. Remarkably, they can be engineered and become able to produce huge and complex molecules, like different kinds of carotenoids, isoprenoids and steroids, in a single fermentation step starting from sugar or alcohol. This composite class of compounds finds many and different applications starting from food (carotenoids and their derivatives are often used as food additives for their antioxidant properties and their coloring capability; isoprenoids are traditionally valued as flavors and fragrances) to pharmaceuticals, acting mainly as anti-aging (carotenoids), hormones (isoprenoids) and as anti-inflammatories (steroids). Tradi- 
tionally these compounds were extracted from their natural producers, mainly plants. Despite the fact that all organisms use them for basic cellular processes, it is in the plant kingdom that their structure and function has most significantly evolved and diversified. To obtain the desired molecule, in some cases a simple extraction was insufficient, chemical steps to convert the crude material into the desired compound were necessary. Starting in the 1990s, it was clear that the market would face competition from Asian countries combined with the negative consumer perception of chemically derived compounds. For these reasons the development of new and alternative production processes requiring only one fermentation step and utilizing natural sources became highly desirable. Here is one example of a long and successful story regarding the engineering of yeast cells for the production. Hydrocortisone, the major steroid (or more precisely, glucocorticoid) in mammals, is the preferred starting material for the synthesis of drugs with anti-inflammatory and also antiproliferative effects. Before the development of a fully ME process, the molecule was obtained through a process of about 40 different steps, which was only partially simplified later on.

Steroid biosynthesis in mammals requires five enzymatic steps, one of which is catalyzed by a highly specialized enzyme, a cytochrome $\mathrm{P} 450$ monooxygenase. It proceeds in a 3-D network, where the intermediates can be the substrates for more than one enzyme, resulting in an array of products obtained with a minimum number of enzymes and steps. So, despite the entire pathway leads to hydrocortisone as the main product, this is not the only one. This fact, responding so well to biological meaning, complicates the possibility of exploiting the pathway for the production of the sole hydrocortisone. Finally, it has to be considered that all the steps are membrane associated, increasing once more the complication of transferring the pathway into a different host system. Despite these premises, a long-term project was started in the early 1980 s in order to obtain a strain of $S$. cerevisiae able to produce hydrocortisone from a simple carbon source in a single fermentation step. It has to be said that with the exception of ergosterol, yeasts do not make any steroids. The goal was finally reached when 13 different genes were assembled and expressed in a single yeast strain [Szczebara et al., 2003]. Eight of the heterologous genes expressed were coding for mammalian proteins and were necessary to redirect the natural yeast production of ergosterol, while the others were necessary to optimize and minimize unwanted side reactions.

\section{Bulk Chemicals for Industrial Applications}

Applying an IB approach, it is now possible to produce in large quantities chemicals like biofuels, glycerol, pyruvate, organic acids, etc., using microorganisms (genetically modified or not) and renewable resources. Just to give an example, bioethanol (alcohol or ethyl alcohol) is produced by fermenting sugars. Today the leading countries for bioethanol production are Brazil $\left(17 \times 10^{6} \mathrm{t}\right)$ and the USA $\left(15.1 \times 10^{6} \mathrm{t}\right)$. It is the main biofuel produced, for example, in China. In $20051.02 \times 10^{6} \mathrm{t}$ were produced in China and the Chinese government is planning to reach a production of $6 \times 10^{6}$ t by 2010 and $15 \times 10^{6} \mathrm{t}$ by 2020 [Italia Oggi, Dec. 9, 2006]. Among the other compounds, special mention has to be made for organic acids, particularly for the bifunctional ones, because this feature allows their use in the construction of many different (homo and hetero) polymers with desirable and innovative characteristics and performances. Here we report one example of a successful story regarding the engineering of yeast cells for the production of lactic acid. L-Lactic acid, first discovered by the Swedish chemist Scheele in 1780 , has been traditionally used as a food preservative and food flavoring compound [Benninga, 1990]. It also finds applications in cosmetics and pharmaceuticals. The worldwide production of lactic acid (currently an estimated 250,000 t/year) [Bizzari and Kishi, 2003; van Maris et al., 2004] is rapidly increasing mainly as a result of the growing market for polylactic acid. It is expected that this biodegradable polymer, produced from renewable resources, will replace various petrochemicalbased polymers in applications ranging from packaging to fibers. This carboxylic acid is currently mainly produced using lactic acid bacteria, such as various lactobacillus species, via an anaerobic fermentation that operates optimally at $\mathrm{pH}$ values where the salt of the organic acid rather than the free acid is formed, although free lactic acid is preferred for most industrial processes [Benninga, 1990]. Different research teams have been involved in the production of lactate from metabolic engineered yeasts such as S. cerevisiae [Dequin and Barre, 1994; Porro et al., 1995; Ansanay et al., 1996; Skory 2003; van Maris et al., 2004; Colombie and Sablayrolles, 2004; Ishida et al., 2006; Saitoh et al., 2005.], K. lactis [Porro et al., 1999; Bianchi et al., 2001], Torulaspora delbrueckii [Porro et al., 1999], P. stipitis [Ilmen et al., 2007] and Z. bailii [Branduardi et al., 2004]. The use of microorganisms like yeasts that are more tolerant to low $\mathrm{pH}$ values than the current production organisms could strongly decrease the amount of neutralizing agents required and lower the cost of down- 


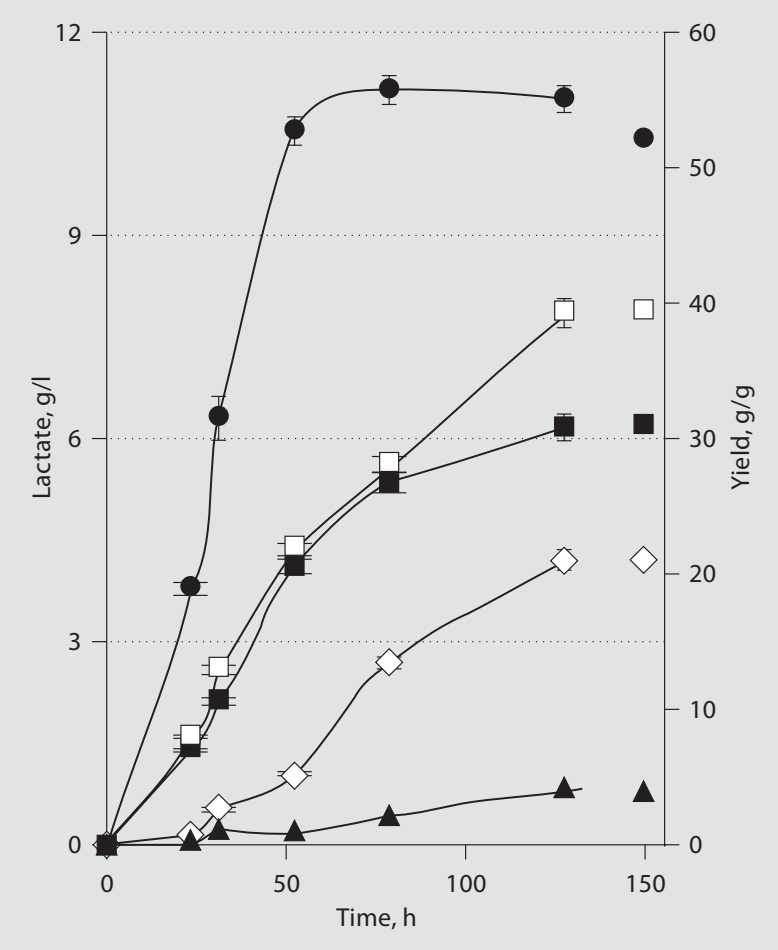

Fig. 3. Summary of the production and yield values that can be achieved from the same S. cerevisiae strain (GRF18U) bearing different $\mathrm{LDH}$ growing under the same physiological conditions on $2 \% \mathrm{wv}^{-1}$ glucose-YNB. Different recombinant S. cerevisiae GRF18U cells were grown in a shake-flask with glucose $2 \% \mathrm{wv}^{-1}$ minimal selective medium until the stationary phase. Samples were collected at indicated times $(\mathrm{h})$ for lactate $(\mathrm{g} / \mathrm{l})$ and yield (g lactate produced/g glucose consumed) determinations: $\boldsymbol{\Delta}=B$. taurus $L D H$ (yield $4 \pm 0.2 \%$ ); $\diamond=L$. casei $L D H$ (yield $21 \pm 0.4 \%$ ); च = L. plantarum LDH (yield $31 \pm 0.5 \%$ ); $\square=$ L. plantarum $L D H$ + ScJEN1 (yield $39 \pm 0.5 \%$ ); $\bullet$ mutated L. plantarum $L D H$ (yield $52 \pm 0.7 \%)$.

stream processing. Pyruvate is the end product of glycolysis; it can be further metabolized either by the pyruvate dehydrogenase complex (Pdh, EC 1.2.4.1) to acetylcoenzyme A or by pyruvate decarboxylase (Pdc, EC 4.1.1.1) to acetaldehyde and subsequently to ethanol. We analyzed the lactate production from metabolic engineered S. cerevisiae cells expressing a heterologous lactate dehydrogenase $(L D H)$ gene. The $L D H$ gene expression in a budding yeast cell introduces a novel and alternative pathway for the $\mathrm{NAD}^{+}$regeneration, allowing a direct reduction of the intracellular pyruvate to lactate, leading to a simultaneous accumulation of lactate and ethanol [Porro et al., 1995]. Four different S. cerevisiae strains were transformed with six different wild-type and one muta- genized $L D H$ genes, in combination or not with the overexpression of a lactate transporter. The resulting yield values (grams of lactate produced per grams of glucose consumed) varied from as low as 0.0008 to as high as $0.52 \mathrm{~g} / \mathrm{g}$. (fig. 3). In this respect, and to the best of our knowledge, higher redirections of the glycolysis flux have never been obtained before without any disruption and/ or limitation of the competing biochemical pathways [Branduardi et al., 2006b]. Only following partial or full replacement of the ethanol production by lactate production, obtained in recombinant yeast cells lacking the Pdc and/or Pdh activities, has it been possible to obtain lactate production with high yield (maximum reported yield 0.85 , i.e., grams of lactate produced per gram of glucose consumed) values [Bianchi et al., 2001].

\section{Conclusions and Perspectives}

Evolution has produced a huge variety of organisms living in radically different environments. Some of these organisms have evolved metabolic pathways leading to the synthesis of potentially useful compounds that are difficult to produce by chemical industry or that are environmentally harmful to manufacture. It has to be remembered that the fundamental basis of evolution is the need to survive and reproduce, not to produce potentially important and commercially valuable products. Indeed, interesting metabolites are very often produced by wild-type organisms in such low concentrations that biotechnological exploitation is today still impractical. ME allows, sometimes in a quite simple way, the development of new microorganisms leading to the production of new products. The existing ME applications are the results of less than two decades of global experience in developing processes for the production of fine chemicals, vitamins, nutraceuticals and animal nutritional aids such as amino acids. The first driving force behind industrial ME applications is the constant increase in the production volumes of carbohydrate raw materials worldwide. In this respect, it is often claimed that glucose could become 'the naphtha of tomorrow'. The second driving force is the continuous decline in manufacturing cost of biotechnologically produced products compared to the increasing cost of the chemically manufactured ones. In this respect the reader is invited to read a quite exhaustive review recently published [Kern et al., 2007] in which the ME of the primary pathways of bacteria, yeast and filamentous fungi is described. Scientists and engineers should recognize, however, that only a few of these studies find real industrial application. In this re- 
spect, the more relevant one is probably the production of 1,3-propandiol, or PDO, from a recombinant E. coli fermentation process on corn sugar, a renewable resource [http://www2.dupont.com/Sorona/en_US/index.html].

Unfortunately, the majority of the ME processes, besides the challenges encountered during the research and development phase, fail during the scale-up phase. Indeed, in an industrial process, the microorganism used as a means of production, is exposed to several stresses that can lead to lower production, lower productivity and lower yield of the product. Stress is typically caused by stressors (or stimuli), i.e. agents of a physical, chemical or biological nature that represent a change in the usual intracellular or extracellular conditions. Stressors require the cell to dedicate more effort to maintaining its natural equilibrium. This greater effort can lead to a higher or lower metabolic activity, lower growth rate, lower viability, or lower productivity, among others. Unfortunately, the classic example of an internally originating stress is the product (protein or metabolite) production itself. Examples of external stress include high osmolarity, high salinity, oxidative stress, non-optimal temperature and $\mathrm{pH}$, presence of organic acids, presence of toxic compounds, and macro- and micronutrient starvation. Often, these are physiological growth conditions imposed by the industrial process itself.

At the cellular level, stress can damage DNA, lipids, proteins, membranes, and other molecules and macromolecules, induce apoptosis (programmed cell death), cell necrosis and cell lysis, and impair cell integrity, and cell viability. These effects are often mediated by the generation of reactive oxygen species (ROS) [for recent reviews see, Kim et al., 2006; Skulachev, 2006].

One example of an industrial process known to be hampered by stress responses is the production of lactic acid by bacteria or yeast (see above). During a typical lactic acid fermentation, the accumulation of lactic acid in the medium causes a drop in the $\mathrm{pH}$ of the medium itself: the organic free acid diffuses through the membrane and dissociates in the higher $\mathrm{pH}$ of the cytoplasm lowering it. The accumulation of lactic acid inhibits cell growth and metabolic activity. The toxicity of this stress is mediated at least in part by ROS. As a result, the extent of lactic acid production is greatly reduced by the accumulation in the medium of lactic acid itself. The neutralization of the fermentation medium obtained with the addition of $\mathrm{Ca}(\mathrm{OH})_{2}, \mathrm{CaCo}_{3}, \mathrm{NaOH}$, or $\mathrm{NH}_{4} \mathrm{OH}$ has major disadvantages since additional operations are required to regenerate free lactic acid from its salt and to dispose of or recycle the neutralizing cation, with a cost increase for the pro- cess. Recombinant yeasts that are engineered for the industrial production of free lactic acid, and, in particular, recombinant yeast from strains showing greater tolerance to extreme environmental conditions have been described above. While these recombinant strains show improved efficiency of lactic acid production at low $\mathrm{pH}$, they are still adversely affected by stress. It is therefore desirable for a ME approach to consider strategies for minimizing stress. In this respect, we developed a metabolically engineered yeast strain capable of producing ascorbic acid and we proved that it acquires increased robustness. Ascorbic acid is a known antioxidant that is produced in all higher plants and many higher animals. Ascorbic acid has been shown to modulate the heat shock response in yeast through an effect on ROS [Moraitis and Curran 2004], and to improve cell viability and reduce proteolysis of the end product of high cell density fermentation [Xiao et al., 2006]. We have shown that recombinant yeasts that are functionally transformed to produce L-ascorbic acid, the biologically active enantiomer, produce lower levels of ROS and exhibit improved growth and viability under conditions of low $\mathrm{pH}$, oxidative stress, and in the presence of high concentrations of lactic acid. These effects suggest that ascorbic acid could improve stress tolerance in general in organisms utilized for industrial production [Branduardi et al., 2005, 2006a, b; US Patent EV 512294478 US].

Finally, we would like to underline that often researchers and engineers look at the producing microbial population as a single entity. It is also a common belief that in a single strain culture all cells behave homogeneously. Unfortunately, this is not the case. Any data obtained represent the average of the weighted contribution of any single cell. It could even be speculated that single cells have quite different production, productivity and yield of the product of interest. In fact, single cells differ among themselves because of their age, dimension, biochemical composition, cell cycle distribution, DNA content, just to mention a few. To further investigate this aspect, a great tool is represented by flow cytometry, because of its unique ability to analyze several parameters of a large number of single cells simultaneously. Flow cytometry has changed our understanding of the behavior of cells in culture, population dynamics, even clonal populations. It has shown that in reality quite surprising variations are present in a population. These variations may be caused both by genetic or epigenetic alterations or by different reactions of the individual cell to culture conditions. Flow cytometric analysis of cells in culture has shown that, with the exception of DNA content, all other cellular components are distrib- 
uted over a wide range, which is the reason why flow cytometry histograms are often on a logarithmic scale. This variation in cellular properties is of special interest for strain improvement purposes, as it allows the sorting of cells with diverging - and potentially optimized - properties. The potential applications are widespread and very versatile, being confined mainly by the technical potentials of the sorting method. Biotechnological applications can be the screening for specific features of biomolecules, mainly proteins, or the screening for cells with specific superior features. The interested reader is referred to a quite exhaustive review recently published by Mattanovich and Borth [2006]. The improvement in cellular properties like viability or stress tolerance may result in improved overproduction of a desired biotechnological product. As an obvious example of the potential of flow cytometry in this respect, it was demonstrated that the screening for recombinant yeast cells producing L-lactic acid with enhanced resistance to weak organic acids in an acidic environment leads directly to strains with an en- hanced ability to produce lactic acid. Based on the observation that cells with a higher intracellular $\mathrm{pH}$ have a better tolerance to acidic conditions, a flow cytometry sorting strategy was performed to screen for cells within the highest range of intracellular $\mathrm{pH}$. The resulting clones with a higher tolerance to an acidic environment also had a higher productivity of lactic acid [Valli et al., 2006].

In conclusion, the ability to produce numerous compounds and chemicals using ME of microorganisms and renewable resources will offer alternatives to the use of petroleum, with clear environmental benefits. The task at stake is huge and requires a sincere collaboration between public and private research facilities, universities, and governments. Knowledge in genetics, biochemistry, molecular biology, fermentation technologies, and process engineering need to be integrated, always taking into consideration the challenges imposed by the scale-up and downstream phases of the process. Public education policies to help the commercialization of IB products will have to be designed.

\section{References}

-Ansanay V, Dequin S, Camarasa C, Schaeffer V, Grivet JP, Blondin B, Salmon JM, Barre P: Malolactic fermentation by engineered Saccharomyces cerevisiae as compared with engineered Schizosaccharomyces pombe. Yeast 1996; 12:215-225.

Bailey JE: Toward the science of met engineering. Science 1991;252:1668-1674.

Benninga H: A History of Lactic Acid Making. Dordrecht, Kluwer Academic, 1990.

Bianchi MM, Brambilla L, Protani F, Liu CL, Lievense J, Porro D: Efficient homolactic fermentation by Kluyveromyces lactis strains defective in pyruvate utilization and transformed with the heterologous $L D H$ gene. Appl Environ Microbiol 2001;67:5621-5625.

Bio - Biotechnology Industry Organization: Guide to Biotechnology. http://www.bio.org/ speeches/pubs/er/BiotechGuide2007.pdf.

Bizzari SN, Kishi A: Lactic Acid, Its Salts and Esters. Chemical Economics Handbook. Menlo Park, SRI International, 2003.

-Blondeau K, Boze H, Jung G, Moulin G, Galzy P. Physiological approach to heterologous human serum albumin production by Kluyveromyces lactis in chemostat culture. Yeast 1994; 10:1297-1303.

Branduardi P, Pagani R, Papini M, Fossati T, Porro D: L-Ascorbic acid production from D-glucose in metabolic engineered Saccharomyces cerevisiae and its effect on strain robustness. International Specialised Symposium on Yeast. ISSY25, Systems Biology of Yeast - From Models to Applications. Hanasaari, Espoo, Finland, June 2006a.
Branduardi P, Sauer M, De Gioia L, Zampella G, Valli M, Mattanovich D, Porro D: Lactate production yield from engineered yeasts is dependent from the host background, the lactate dehydrogenase source and the lactate export. Microb Cell Fact 2006b;30:5: 4-15.

Branduardi P, Sauer M, Mattanovich D, Porro D: Ascorbic acid production from D-glucose in yeast. Application for United States Letters Patent. 2005 Serial No. EV 512294478 US.

Branduardi P, Valli M, Brambilla L, Sauer M, Alberghina L, Porro D: The yeast Zygosaccharomyces bailii: a new host for heterologous protein production, secretion and for metabolic engineering applications. FEMS Yeast Res 2004;4:493-504.

BREW - Medium and Long-Term Opportunities and Risks of the Biotechnological Production of Bulk Chemicals from Renewable Resources - Final Report. Prepared under the European Commission's GROWTH program. Utrecht, September 2006 http://www. chem.uu.nl/brew/programme.html.

Buckholz RG, Gleeson MA: Yeast systems for the commercial production of heterologous proteins. Biotechnology (NY) 1991;9:1067-1072.

Cameron DC, Chaplen FW: Developments in metabolic engineering. Curr Opin Biotechnol 1997;8:175-180.

Cameron DC, Tong IT: Cellular and metabolic engineering. An overview. Appl Biochem Biotechnol 1993;38:105-140.

-Cardona F, Carrasco P, Perez-Ortin JE, Del Olmo ML, Aranda A: A novel approach for the improvement of stress resistance in wine yeasts. Int J Food Microbiol 2007;114:83-91.

Colombie S, Sablayrolles JM: Nicotinic acid controls lactate production by K1-LDH: a Saccharomyces cerevisiae strain expressing a bacterial $L D H$ gene. J Ind Microbiol Biotechnol 2004;31:209-215.

Den Haan R, Van Zyl WH: Differential expression of the Trichoderma reesei beta-xylanase II (xyn2) gene in the xylose-fermenting yeast Pichia stipitis. Appl Microbiol Biotechnol 2001;57:521-527.

Dequin S, Barre P: Mixed lactic acid-alcoholic fermentation by Saccharomyces cerevisiae expressing the Lactobacillus case $i \mathrm{~L}(+)-\mathrm{LDH}$. Biotechnology (NY) 1994;12:173-177.

DuPont www2.dupont.com/Sorona/en_US/index.html.

Gasch AP, Spellman PT, Kao CM, Carmel-Harel $\mathrm{O}$, Eisen MB, Storz G, Botstein D, Brown PO: Genomic expression programs in the response of yeast cells to environmental changes. Mol Biol Cell 2000;11:4241-4257.

Goffeau A, Barrell BG, Bussey H, Davis RW, Dujon B, Feldmann H, Galibert F, Hoheisel JD, Jacq C, Johnston M, Louis EJ, Mewes HW, Murakami Y, Philippsen P, Tettelin H, Oliver SG: Life with 6000 genes. Science 1996;274: 546-567.

-Ilmen M, Koivuranta K, Ruohonen L, Suominen P, Penttila M: Efficient Production of L-lactic acid from xylose by Pichia stipitis. Appl Environ Microb 2007;73:117-123.

Ishida N, Saitoh S, Onishi T, Tokuhiro K, Nagamori E, Kitamoto K, Takahashi H: The effect 
of pyruvate decarboxylase gene knockout in Saccharomyces cerevisiae on L-lactic acid production. Biosci Biotechnol Biochem 2006;70:1148-1153.

-Kern A, Tilley E, Hunter IS, Legisa M, Glieder A: Engineering primary metabolic pathways of industrial micro-organisms. J Biotechnol 2007;129:6-29.

-Kim R, Emi M, Tanabe K, Murakami S, Uchida Y, Arihiro K: Regulation and interplay of apoptotic and non-apoptotic cell death. J Pathol 2006;208:319-326.

Mattanovich D, Borth N: Applications of cell sorting in biotechnology. Microb Cell Fact 2006;5:12-22.

Malherbe DF, du Toit M, Otero RRC, van Rensburg P, Pretorius IS: Expression of the Aspergillus niger glucose oxidase gene in Saccharomycescerevisiae and its potential applications in wine production. Appl Microbiol Biotechnol 2003;61:502-511.

-Moraitis C, Curran BPG: Reactive oxygen species may influence the heat shock response and stress tolerance in the yeast Saccharomyces cerevisiae. Yeast 2004;21:313-323.

-Muller S, Sandal T, Kamp-Hansen P, Dalboge H: Comparison of expression systems in the yeasts Saccharomyces cerevisiae, Hansenula polymorpha, Klyveromyces lactis, Schizosaccharomyces pombe and Yarrowia lipolytica. Cloning of two novel promoters from Yarrowia lipolytica. Yeast 1998;14:1267-1283.

-Nielsen J: Metabolic engineering: techniques for analysis of targets for genetic manipulations. Biotechnol Bioeng 1998;58:125-132.

Nielsen J: Metabolic engineering. Appl Microbiol Biotechnol 2001;55:263-283.

-Ogawa Y, Tatsumi H, Murakami S, Ishida Y, Murakami, K, Masaki A, Kawabe $\mathrm{H}$, Arimura $\mathrm{H}$, Nakano E, Motai H, et al: Secretion of Aspergillus oryzae alkaline protease in an osmophilic yeast, Zygosaccharomyces rouxii. Agric Biol Chem 1990;54:2521-2529.

- Ostergaard S, Olsson L, Johnston M, Nielsen J: Increasing galactose consumption by $\mathrm{Sac}$ charomyces cerevisiae through metabolic engineering of the GAL gene regulatory network. Nat Biotechnol 2000;18:1283-1286.

Porro D, Bianchi MM, Brambilla L, Menghini R, Bolzani D, Carrera V, Lievense J, Liu CL, Ranzi BM, Frontali L, Alberghina L: Replacement of a metabolic pathway for largescale production of lactic acid from engineered yeasts. Appl Environ Microbiol 1999; 65:4211-4215.

- Porro D, Brambilla L, Ranzi BM, Martegani E, Alberghina L: Development of metabolically engineered Saccharomyces cerevisiae cells for the production of lactic acid. Biotechnol Prog 1995;1:294-308.

Pretorius IS: Tailoring wine yeast for the new millennium: novel approaches to the ancient art of winemaking. Yeast 2000;16:675-729.

- Pretorius IS, du Toit M, van Rensburg P: Designer yeasts for the fermentation industry of the 21st century. Food Technol Biotechnol 2003; 41:3-10.
Raymond CK, Bukowski T, Holderman SD, Ching AFT, Vanaja E, Stamm MR: Development of the methylotrophic yeast, Pichia methanolica, for the expression of the 65-kilodalton isoform of human glutamate decarboxylase. Yeast 1998;14:11-23.

Remize F, Andrieu E, Dequin S: Engineering of the pyruvate dehydrogenase bypass in Saccharomyces cerevisiae: role of the cytosolic $\mathrm{Mg}(2+)$ and mitochondrial $\mathrm{K}(+)$ acetaldehyde dehydrogenases Ald6p and Ald4p in acetate formation during alcoholic fermentation. Appl Environ Microbiol 2000;66: 3151-3169.

Rossignol T, Dulau L, Julien A, Blondin B: Genome-wide monitoring of wine yeast gene expression during alcoholic fermentation. Yeast 2003;20:1369-1385.

Sachtleben L: Products from Petroleum. Chevron World Magazine, Winter, 1990.

- Saitoh S, Ishida N, Onishi T, Tokuhiro K, Nagamori E, Kitamoto K, Takahashi H: Genetically engineered wine yeast produces a high concentration of L-lactic acid of extremely high optical purity. Appl Environ Microbiol 2005;71:2789-2792.

Sakai Y, Rogi T, Takeuchi R, Kato N, Tani Y: Expression of Saccharomyces adenylate kinase gene in Candida boidinii under the regulation of its alcohol oxidase promoter. Appl Microbiol Biotechnol 1995;42:860-864.

- Schuller D, Casal M: The use of genetically modified Saccharomyces cerevisiae strain in wine industry. Appl Microbiol Biotechnol 2005; 68:292-304.

-Skory CD: Lactic acid production by Saccharomyces cerevisiae expressing a Rhizopus oryzae lactate dehydrogenase gene. J Ind Microbiol Biotechnol 2003;30:22-37.

-Skulachev VP: Bioenergetic aspects of apoptosis, necrosis and mitoptosis. Apoptosis 2006;11: 473-485.

Smalley RE: http://smalley.rice.edu/emplibrary/ columbia09232003.ppt. Power Point slides that Dr. Smalley, 1996 Nobel Laureate, used with his testimony to the Senate Committee on Energy and Natural Resources; Hearing on sustainable, low emission, electricity generation, April 27, 2004, see http://smalley. rice.edu/emplibrary/Senate_20040427.pdf for full text of the testimony.

-Stephanopoulos G: Metabolic engineering. Curr Opin Biotechnol 1994;5:196-200.

-Stephanopoulos G: Metabolic fluxes and metabolic engineering. Metab Eng 1999;1:1-11.

-Stephanopoulos G, Sinskey AJ: Metabolic engineering - methodologies and future prospects. Trends Biotechnol 1993;11:392-406.

-Stephanopoulos G, Vallino JJ: Network rigidity and metabolic engineering in metabolite overproduction. Science 1991;252:16751681.

- Sudbery PE, Gleeson MA, Veale RA, Ledeboer AM, Zoetmulder MC: Hansenula polymorpha as a novel yeast system for the expression of heterologous genes. Biochem Soc Trans 1988;16:1081-1083.
Suschem - European Technology Platform for Sustainable Chemistry: Vision paper 2005. http://www.suschem.org/content.php?_doc ument[ID] $=2049$ \&pageId $=3217$.

- Sutherland CM, Henschke PA, Langridge P, Lopes MD: Subunit and cofactor binding of Saccharomyces cerevisiae sulfite reductase towards developing wine yeast with lowered ability to produce hydrogen sulfide. Aust J Grape Wine Res 2003;9:186-193.

-Szczebara FM, Chandelier C, Villeret C, Masurel A, Bourot S, Duport C, Blanchard S, Groisillier A, Testet E, Costaglioli P, Cauet G, Degryse E, Balbuena D, Winter J, Achstetter T, Spagnoli R, Pompon D, Dumas B: Total biosynthesis of hydrocortisone from a simple carbon source in yeast. Nat Biotechnol 2003; 21:143-149.

Thill G, Davis G, Stillman C, Tschopp JF, Craig WS, Velicelebi G, Greff J, Akong M, Stroman D, Torregrossa R, Siegel RS: The methylotrophic yeast Pichia pastoris as a host for heterologous protein production; in van Verseveld HW, Duine JA (eds): Microbial Growth on C1 Compounds. Dordrecht, Nijhoff, 1987, pp 289-296.

Tyo KE, Alper HS, Stephanopoulos GN: Expanding the metabolic engineering toolbox: more options to engineer cells. Trends Biotechnol 2007;25:132-137.

United Nations Environment Programme World Meteorological Organization. http:// www.gcrio.org/ipcc/qa/02.html.

US Department of Energy: Industrial bioproduct today and tomorrow. 2003. http://www. brdisolutions.com/pdfs/BioProductsOpportunitiesReportFinal.pdf.

US Department of Energy: Top value added chemicals from biomass. 2004. http://wwwl. eere.energy.gov/biomass/pdfs/35523.pdf; US Government, Official Energy Statistics www.eia.doe.gov.

Valli M, Sauer M, Branduardi P, Borth N, Porro D, Mattanovich D: Improvement of lactic acid production in Saccharomyces cerevisiae by cell sorting for high intracellular $\mathrm{pH}$. Appl Environ Microbiol 2006;72:54925499.

van Maris AJ, Winkler AA, Porro D, van Dijken JP, Pronk JT: Homofermentative lactate production cannot sustain anaerobic growth of engineered Saccharomyces cerevisiae: possible consequence of energy-dependent lactate export. Appl Environ Microbiol, 2004;70: 2898-2905.

-Waché Y, Husson F, Feron G, Belin JM: Yeast as an efficient biocatalyst for the production of lipid-derived flavours and fragrances. Antonie Van Leeuwenhoek 2006;89:405-416.

Xiao A, Zhou X, Zhou L, Zhang Y: Improvement of cell viability and hirudin production by ascorbic acid in Pichia pastoris fermentation. Appl Microbiol Biotechnol 2006;72:837844.

World Energy Council www.worldenergy.org. 